\title{
Acute Limb Ischemia in a Child: Case Report
}

\author{
Ihssane Cherrabi", Said Benlamkkadem, Adnane Berdai, Mustapha Harrandou
}

Maternal and pediatric intensive care unit Hassan II university hospital Fez, Morocco

DOI: $10.36347 /$ sasjm.2021.v07i05.005

| Received: 29.03.2021 | Accepted: 07.05.2021 | Published: 16.05.2021

*Corresponding author: Ihssane Cherrabi

\section{Abstract}

Limb ischemia in pediatric population is a rare but potentially catastrophic event; it can lead to death of nerve and then muscle tissue within 4 to 6 hours unless the limb is revascularized. The most appropriate diagnostic and therapeutic strategy has evolved with emerging technologies inclusive of less-invasive endovascular diagnostic and therapeutic options. We report the case of a 5-year-old patient with acute limb ischemia (ALI), to illustrate the diagnostic and therapeutic approaches and the peculiarity in pediatric population.

Keywords: Pediatric, Acute limb ischemia, thrombosis, thromboembolism.

Copyright ( 2021 The Author(s): This is an open-access article distributed under the terms of the Creative Commons Attribution 4.0 International License (CC BY-NC 4.0) which permits unrestricted use, distribution, and reproduction in any medium for non-commercial use provided the original author and source are credited.

\section{INTRODUCTION}

Acute arterial Limb ischemia (ALI) is a lifethreatening emergency which also compromises the functional prognosis of the limb. It is a rare event in pediatric population, consequence of abrupt interruption of arterial flow [1].

Given the rarity of ALI in pediatrics, physicians and surgeons caring for those cases are usually guided by consensus guidelines that mostly extrapolate from the adult literature rather than from well-designed perspective studies in the pediatric population [2].

\section{CASE REPORT}

We report the case of a 5-year-old patient, with a history of bilateral pleurisy, admitted in the intensive care unit with a 1-day history of pain in his lower limbs, coldness and pallor. His mother reported a history of a deep vein thrombosis in the lower right limb during her pregnancy. The clinical exam did not find the pedal pulse. Thrombophilia biological tests were abnormal with a deficit of s protein and antithrombin III. The CT angiography found a total occlusion of the external left iliac artery.

The child had an embolectomy. Despite the early management, the patient had a recurrence of the thrombosis with necrosis of the left lower limb that required a transfemoral amputation. The evolution was marked by a third episode of ischemia in the contralateral lower limb, a CTA found a floating thrombus on the aorta, a total stenosis of the left common iliac artery and the deep iliac artery, with an incomplete stenosis of the left iliac artery. This thromboembolic disease was due to a resistance to the unfractionated heparin. We switched the treatment to anti vitamin $\mathrm{K}$ with a favorable evolution.

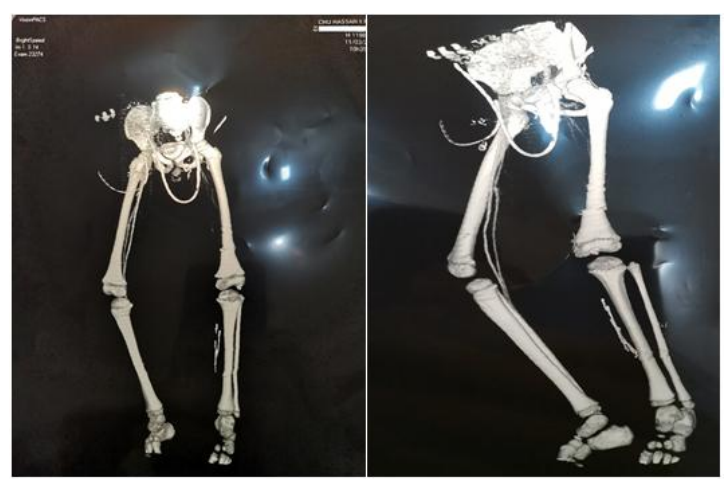

Fig-1: CT angiography

\section{DISCUSSION}

ALI is an infrequent but potentially devastating condition in the pediatric population. It is usually posttraumatic or iatrogenic and is rarely secondary to arterial occlusive disease as in the adult population [3].

In contrast to adults, most studies describing the clinical and operative management of ALI in pediatric patients suggest that, this condition can generally be managed successfully with anticoagulation. This is likely because neonates and children differ from adults in physiology, pharmacologic responses to anticoagulation, epidemiology, and long-term consequences of 
thrombosis, as well as in an enhanced ability to form a collateral vascular supply to the limbs $[3,4]$.

In the absence of data from prospective trials, the timing of an operation for ALI in pediatric patients varies by institution. No specific guidelines exist for the use of thrombectomy in children, but the general consensus is that the recurrence rate and risk of longterm vascular damage is high $[4,5]$.

In our case, we started by a surgical treatment, hoping to quickly reestablish the arterial flow unfortunately he developed postoperatively a resistance to LMWH which led to the amputation.

As a general rule, patients with clinical evidence of limb ischemia, such as pulselessness or hypothermia, and radiologic evidence of absent blood flow in the affected limb, in the absence of contraindications, should start by a 24-hour trial of anticoagulation of unfractionated heparin or LMWH [4], unless they had significant motor or sensory loss at the time of presentation with ALI. Those who showed no clinical or radiologic evidence of clot resolution after 24 hours were considered for a trial of thrombolysis using tissue plasminogen activator (tPA). If the tPA therapy failed, patients are then offered a surgical intervention[1].

The duration of anticoagulation in pediatric ALI is also subject to consensus guidelines rather than prospective data [1]. Current guidelines recommend a 5- to 7-days course of therapeutic anticoagulation with unfractionated heparin or LMWH for neonates or children with acute femoral artery thrombosis [4]. There are no guidelines, however, for the management of thrombosis in other arteries or in patients who demonstrate clinical improvement but lack of clot resolution on Doppler ultrasound imaging, high-risk patients with a history of clotting disorders, or patients with concurrent asymptomatic venous thrombosis.

As such, anticoagulation therapy was continued in our patient for 6 months, until there was evidence of clot resolution on imaging. The testing of pediatric patients with ALI for underlying hypercoagulable states is a topic of controversy, moreover, the current treatment guidelines for ALI are indifferent to whether a pediatric patient has a heritable hypercoagulable state [4].

Functional protein assay tests for protein $\mathrm{C}$, protein $\mathrm{S}$, or antithrombin may also be inaccurate in patients who are on existing anticoagulation therapy or if ordered at the time of an acute thrombotic event. For example, a recent audit by a pediatric center in New Zealand demonstrated that only $37 \%$ of tests with abnormal results were repeated for confirmation of conditions such as antithrombin and proteins $\mathrm{C}$ or $\mathrm{S}$ deficiency, despite evidence that such diagnoses should not be made from a single set of results [6]. Furthermore, current British guidelines only recommend protein $\mathrm{C}$ and $\mathrm{S}$ deficiency testing in neonates with purpura fulminans. These guidelines do not recommend a hypercoagulable workup in patients with arterial thrombosis or in asymptomatic relatives with low-risk thrombophilia [7].

\section{CONCLUSION}

On the basis of our observation and the literature review we conclude that:

- Management by a multidisciplinary team that includes vascular surgeons, hematologists, medical imaging, and pediatric intensive care physicians is necessary to achieve a successful outcome in pediatric patients who present with ALI.

- In subclinical pediatric patients, a trial of conservative management with appropriate anticoagulation is justified due to the less favorable outcomes with surgery in this age-group.

- Surgery should be performed when limb loss is imminent and therapeutic anticoagulation/ thrombolysis has failed.

\section{REFERENCES}

1. Kayssi A, Shaikh F, Roche-Nagle G, Brandao LR, Williams SA, Rubin BB. Management of acute limb ischemia in the pediatric population. Journal of Vascular Surgery. 1 Juill. 2014;60(1):106- 10.

2. $A B C$ of arterial and venous disease: Acute limb ischaemia. BMJ. 8 avr 2000;320(7240):991.

3. Sadat U, Hayes PD, Varty K. Acute Limb Ischemia in Pediatric Population Secondary to Peripheral Vascular Cannulation: Literature Review and Recommendations. Vasc Endovascular Surg. Août. 2015;49(5-6):142- 7.

4. Monagle $\mathrm{P}$, Chan AKC, Goldenberg NA, Ichord RN, Journeycake JM, Nowak-Göttl U. Antithrombotic therapy in neonates and children: Antithrombotic Therapy and Prevention of Thrombosis, 9th ed: American College of Chest Physicians Evidence-Based Clinical Practice Guidelines. Chest. Févr. 2012;141(2 Suppl):e737Se801S.

5. Price V, Massicotte P. Arterial Thromboembolism in the Pediatric Population. Seminars in thrombosis and hemostasis. 1 Janv. 2004; 29:557- 65.

6. Campos M, Montes-Limón A, FernándezMosteirín N, Salvador-Osuna C, Torres M, LuciaCuesta J. Dosing and monitoring of enoxaparin therapy in children: Experience in a tertiary care hospital. Blood coagulation \& fibrinolysis : an international journal in haemostasis and thrombosis. 1 Mars. 2013; 24:194- 8 .

7. Baglin T, Gray E, Greaves M, Hunt BJ, Keeling D, Machin S. Clinical guidelines for testing for heritable thrombophilia. British Journal of Haematology. 2010; 149(2):209- 20. 